\title{
Membrane-type matrix metalloproteinases: expression, roles in metastatic prostate cancer progression and opportunities for drug targeting
}

\author{
Robert A. Falconer, Paul M. Loadman \\ Institute of Cancer Therapeutics, Faculty of Life Sciences, University of Bradford, Bradford BD7 IDP, UK.
}

Correspondence to: Dr. Robert A. Falconer, Institute of Cancer Therapeutics, Faculty of Life Sciences, University of Bradford, Richmond Road, Bradford BD7 1DP, UK. E-mail: r.a.falconer1@bradford.ac.uk; Prof. Paul M. Loadman, Institute of Cancer Therapeutics, Faculty of Life Sciences, University of Bradford, Richmond Road, Bradford BD7 1DP, UK. E-mail: p.m.loadman@bradford.ac.uk

How to cite this article: Falconer RA, Loadman PM. Membrane-type matrix metalloproteinases: expression, roles in metastatic prostate cancer progression and opportunities for drug targeting. J Cancer Metastasis Treat 2017;3:315-27.

Article history:

Received: 7 Jun 2017

First Decision: 15 Jun 2017

Revised: 18 Oct 2017

Accepted: 26 Oct 2017

Published: 12 Dec 2017

Key words:

Matrix metalloproteinase,

membrane-type,

metastasis,

prostate cancer,

microenvironment

\begin{abstract}
The membrane-type matrix metalloproteinases (MT-MMPs), an important subgroup of the wider MMP family, demonstrate widespread expression in multiple tumor types, and play key roles in cancer growth, migration, invasion and metastasis. Despite a large body of published research, relatively little information exists regarding evidence for MT-MMP expression and function in metastatic prostate cancer. This review provides an appraisal of the literature describing gene and protein expression in prostate cancer cells and clinical tissue, summarises the evidence for roles in prostate cancer progression, and examines the data relating to MT-MMP function in the development of bone metastases. Finally, the therapeutic potential of targeting MT-MMPs is considered. While MT-MMP inhibition presents a significant challenge, utilisation of MT-MMP expression and proteolytic capacity in prostate tumors is an attractive drug development opportunity.
\end{abstract}

\section{INTRODUCTION}

Several decades of research have established the matrix metalloproteinases (MMPs) as key players in the progression of cancer, largely through alterations observed in the tumor microenvironment. Indeed, MMPs have been considered as potential diagnostic and prognostic biomarkers for many types and stages of cancer ${ }^{[1]}$. Despite their potential as therapeutic targets, however, a clinically useful agent has yet to materialise, despite several MMP inhibitors having been developed and evaluated in clinical trials ${ }^{[2]}$. More recently, attention has turned to the potential utility of MMPs as activators of targeted prodrug therapies ${ }^{[3-5]}$.

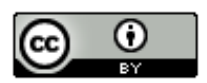

This is an open access article licensed under the terms of Creative Commons Attribution 4.0 International License (https://creativecommons.org/licenses/by/4.0/), which permits unrestricted use, distribution, and reproduction in any medium, as long as the original author is credited and the new creations are licensed under the identical terms.

For reprints contact: service@oaepublish.com

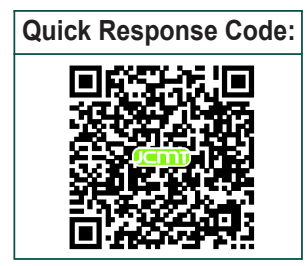


Table 1: MT-MMP nomenclature

\begin{tabular}{ll}
\hline Gene & Protein \\
\hline$M M P-14$ & MT1-MMP \\
MMP-15 & MT2-MMP \\
$M M P-16$ & MT3-MMP \\
$M M P-17$ & MT4-MMP \\
$M M P-24$ & MT5-MMP \\
MMP-25 & MT6-MMP \\
\hline
\end{tabular}

MT-MMP: membrane-type matrix metalloproteinases

The MMP family of proteolytic enzymes comprises over 26 structurally similar zinc-dependent endoproteases. The wider family comprises two major subgroups: (1) the soluble or secreted MMPs and (2) the membrane-type MMPs (MT-MMPs). The MTMMPs are further sub-classified by their cell surface association, either by a transmembrane domain (as is the case for MT1-, MT2-, MT3-, and MT5-MMP) or by a glycophosphatidylinositol anchor (in MT4- and MT6MMP). The nomenclature for the MT-MMPs is outlined in Table 1: the gene and protein names are generally used interchangeably. The structures of the MT-MMP family have been well described ${ }^{[6]}$. They are each synthesised as inactive pre-pro enzymes in the Golgi apparatus, with cleavage of the signal peptide and prodomain required before transport to the cell surface.

The roles played by many MMPs in wider cancer initiation, progression and metastasis have been extensively explored, with pivotal roles described in prostate cancer in particular ${ }^{[7]}$. Expression and the roles played by the MT-MMP family in prostate cancer are less well studied, however, and it is this area that is the focus of this review. The available evidence for expression of MT-MMPs in prostate cancer cells and clinical tissues will be examined first, followed by consideration of their roles in prostate cancer function and in metastasis to the bone.

\section{EXPRESSION OF MT-MMPS IN PROSTATE CANCER CELL LINES}

A significant body of literature exists concerning the expression of MT1-MMP in prostate cancer cell lines, albeit limited almost exclusively to the widely studied PC3, DU145 and LNCaP cell lines. Prostatic adenocarcinoma cells PC3 (derived from a bone metastasis) and DU145 (derived from a brain metastasis) are androgen-insensitive and metastatic (PC3 being the more aggressive of the two), while LNCaP cells (prostatic adenocarcinoma cells derived from a lymph node metastasis) are androgen-sensitive cells and non-metastatic ${ }^{[8]}$.

MT1-MMP gene expression has been consistently reported in the androgen-insensitive, more metastatic cell lines PC3 (and sublines PC3-M and PC3-MM2 ${ }^{[8]}$ ) and DU145. Expression has also been reported in TSU-Pr1 cells ${ }^{[9,10]}$, also androgen-insensitive. Meanwhile, the less aggressive androgen-sensitive cell line LNCaP (and sublines LNCaP-C4 and LNCaP-C4- $2^{[8]}$ ) exhibit low or an absence of MT1MMP gene expression ${ }^{[8,10-13]}$. Daja et al ${ }^{[8]}$ explain that despite these differences in gene expression, active MT1-MMP protein expression was identified in both $\mathrm{LNCaP}$ and PC3 cells and their sublines. Furthermore, Jennbacken et al. ${ }^{[14]}$ demonstrated that transformation of LNCaP into an androgen-independent cell line (i.e. LNCaP-19 ${ }^{[15]}$ ) was accompanied by increased aggressiveness (growth and migratory capacity) and by upregulation of both MT1-MMP gene and protein expression. The influence of the tumor microenvironment, specifically fibroblasts (WPF5), was investigated on PC3 and DU145 cells in a study by Coulson-Thomas et al. ${ }^{[16]}$. An increase in MT1MMP gene and protein expression was reported in cocultures of WPF5 and PC3 or DU145 cells. Protein was localised at the cellular projections of all cell lines. When considered together with changes in vimentin distribution and an up-regulation of integrin a5 $\beta 1$ expression, this is indicative of a more invasive phenotype.

Information regarding the remaining members of the MT-MMP family is more scarce. Interestingly, in contrast to the picture observed with MT1-MMP, MT2$M M P$ gene expression has been reported as more significant in LNCaP cells and sublines than in PC3 cells. The pattern of MT3-MMP gene expression is the opposite to this, and thus similar to that observed for MT1-MMP ${ }^{[8]}$. Protein levels were similar in both cell lines, however. Processed MT-MMPs, indicative of latent MMP activation, were observed to be increased in the more aggressive sublines. Jung et al. ${ }^{[11]}$ described significant gene expression of MT2MMP and MT5-MMP in both cell types. MT3-MMP expression was observed in LNCaP cells with negligible expression in PC3 or DU145 cells. Meanwhile, MT4MMP expression was observed in PC3 and DU145, with negligible expression in LNCaP cells.

\section{EXPRESSION OF MT-MMPS IN PROSTATE CANCER CLINICAL TISSUES}

The clinical expression of secreted MMPs in prostate cancer has been well reviewed by Gong et al. ${ }^{[7]}$, with expression of MMP-2, $-3,-7,-9$ and -13 gene and protein each identified in serum and tumor tissue of patients with prostate cancer, and correlation with progression and metastasis observed. Interestingly, 
MMP-1 expression has been associated with lower grade prostate tumors. In this section, we have summarised the clinical expression data available for MT-MMPs in prostate cancer tissues.

Trudel et al. ${ }^{[17]}$ examined tissues from 189 prostate cancer patients who had undergone surgery (radical prostatectomy). MT1-MMP expression and its effects on disease-free survival were examined immunohistochemically, differentiating cancer, stromal, and benign epithelial cells. This study showed that in $167(88.8 \%)$ cases, MT1-MMP was expressed by benign epithelial cells and MT1-MMP was expressed by cancer cells in 171 (90.5\%) cases. The expression in cancerous tissue was mostly observed in cells at or near the tumor front. Overall the expression was described as heterogeneous though cancer cells at the tumor margin were seen to always express MT1-MMP. The expression of MT1-MMP in benign epithelial cells was somewhat unexpected, given what is generally understood about MMPs in other cancers. The authors did raise the issue of the quality and specificity of commercial antibodies for MT1-MMP, and did further suggest that active MT1-MMP could be cleaved by other MMPs resulting in soluble fragments, which may have been detected. It is the potential effect of prostate cancer cells on the local microenvironment that is perhaps the key, however. The authors speculated as to whether the presence of MT1-MMP in benign epithelial cells (near cancerous tissue) from these patients might in fact be induced by the cancer. A study by Paterson et al. ${ }^{[18]}$ in bladder cancer was crossreferenced, which had further suggested that the socalled "benign" epithelial cells in those patients were in fact not benign at all, but genotypically abnormal. These findings have been encountered by others and are worthy of further study.

Discrepancies between gene expression (higher MT1MMP expression in benign prostate hyperplasia and prostate cancer tissues, when compared to normal prostate) and protein expression (lower expression in prostate cancer tissues compared to normal prostate and benign prostate hyperplasia) were noted by Neuhaus et al. ${ }^{[19]}$. These results contrast with most other published studies, which led the authors to speculate that cells of the prostate interstitium (included in assessment of total immunofluorescence due to MT1-MMP) may have increased protein expression and may account for the apparent levels of protein expression seen in epithelial cells.

Cardillo et al. ${ }^{[20]}$ analysed 38 paraffin-embedded samples from prostate cancer patients (who had undergone radical prostatectomy) by immunohistochemistry and compared prostate intraepithelial neoplasia (PIN) and its normal adjacent prostate (NAP) counterpart. MT1-MMP was observed to be more strongly expressed in tumor tissue than in PIN and NAP tissue, with the expression of MT1-MMP reaching its highest levels in the most aggressive prostate tumors with high Gleason scores (Gleason scores are used to grade prostate cancer, with a score above 7 indicative of aggressive, metastatic disease). Once again, expression was detected in surrounding stroma and epithelia, backing up the findings of Trudel et al. ${ }^{[1]}$. The authors speculate that stromal and tumor cells could co-operate in facilitating tumor cell invasion, hence the requirement for MT1-MMP expression, and that transition from benign epithelium via PIN to cancer is associated with changes in localisation of MT1-MMP in the prostate epithelium ${ }^{[20]}$.

In a further 40 patients, Reis et al. ${ }^{[21]}$ also monitored tissue inhibitor of matrix metalloproteinase 1 (TIMP1) expression together with that of MT1-MMP. TIMPs inhibit some MMPs and other protease enzymes, but not MT1-MMP ${ }^{[22]}$. The loss of TIMP-1 protein expression was correlated to cancer progression, with MT1-MMP protein expression being identified in the majority of prostate cancer specimens. Once again, a positive correlation with Gleason score was observed $^{[21]}$. This reinforced an earlier study by the same group (79 prostate cancer patients), which indicated that MT1-MMP expression was higher in patient samples with Gleason scores $\geq 7$, though that dataset only exhibited marginal statistical significance ${ }^{[23]}$.

Upadhyay et al. ${ }^{[24]}$ investigated the relationship between the MT1-MMP and MMP-2 expression, with immunohistochemistry confirmed by western blotting and gelatin zymography. A significant correlation between the pattern of MMP-2 and MT1MMP expression within the epithelial components of individual specimens was observed. Differential staining was seen between benign epithelia, highgrade PIN, and prostate cancer. In benign glands, the greatest expression for MT1-MMP was in basal cells (BCs), whereas secretory cells were rarely positive. Conversely in high-grade PIN, secretory cells showed consistent cytoplasmic staining. In cancer cells, staining was heterogeneous and varied from no staining to very intense staining in select glands ${ }^{[24]}$.

High expression of insulin-like growth factor-1 receptor (IGF-1R) in prostate cancer was identified by Sroka et al. ${ }^{[25]}$, who suggested that using MT1MMP localization and IGF-1R expression may serve as a predictive biomarker of aggressive disease. MT1MMP expression was high in the apical regions of the 
luminal cells in PIN and prostate cancer cells, though less intense in the basolateral regions of benign tissues. IGF-1R was expressed primarily in the basal cells of normal glands and highly expressed in prostate cancer tissues $^{[25]}$.

As is the case with studies on cell lines, the majority of clinical reports focus on expression of MT1-MMP. Both Jung et al. ${ }^{[11]}$ and Riddick et al. ${ }^{[26]}$ compared a wider range of MT-MMP family member gene expression in paired tissue samples from non-malignant and malignant parts of the same prostate cancer patient biopsies, using real-time polymerase chain reaction (PCR). Interestingly, Jung et al. ${ }^{[11]}$ identified a significant down-regulation for all investigated MTMMPs except for MT2-MMP in malignant tissue and did not detect a correlation between tumor classification and MT-MMP expression. Riddick et al. ${ }^{[26]}$ investigated MT-MMP gene expression in 44 prostate cancer cases and 23 benign prostate hyperplasia specimens, also by real-time PCR. This study additionally found increased gene expression of MT2MMP, MT5-MMP and MT6-MMP in malignant tissue compared to benign prostate tissue, and suggested that these proteases are likely to participate directly in prostate tumor invasion. It is important to note that MT6-MMP was primarily expressed by the epithelial cancer cells rather than stromal cells. The lack of difference in MT1-MMP expression between malignant and local non-malignant tissue perhaps provides further evidence for the conclusions previously discussed ${ }^{[17,18,20]}$.

The evidence for MT-MMP expression, and particularly MT1-MMP expression, in prostate cancer cells and tumors from patients is compelling. The picture is complicated by the involvement of the tumor microenvironment, in which MT-MMP expression is influenced, perhaps initiated, by the development of cancer. In the following section, the roles of individual MMPs are considered, along with links to other pathways known to be important in prostate cancer progression and metastasis.

\section{FUNCTIONS OF MT-MMPS IN PROSTATE CANCER PROGRESSION AND METASTASIS}

It is widely accepted that MT-MMPs play key roles in the metastatic process ${ }^{[27]}$. With regards prostate cancer, MT-MMPs have been identified as contributing towards apoptosis, angiogenesis, proliferation and metastasis $^{[7]}$. MT-MMPs have been shown to be involved in various molecular processes in prostate cancer progression and metastasis, which will now be considered here, together with information regarding potential regulatory pathways. Some of the molecular events associated with MT-MMP expression and function in tumor cell migration, angiogenesis and vascular signalling are summarised in Figure $1^{[28]}$.

MT1-MMP plays a role in epithelial-to-mesenchymal transition (EMT). EMT is an important process in the metastatic cascade, involving multiple oncogenic drivers ${ }^{[29]}$. Cao et al. ${ }^{[30]}$ initially used DNA microarray database mining to reveal upregulation of MT1-MMP in human primary and metastatic prostate cancer samples. Using 3D cell culture models, the study additionally demonstrated that transformation of LNCaP cells with MT1-MMP induced morphological changes and modulation of epithelial and mesenchymal markers consistent with EMT, and thus metastatic transformation. Further experiments demonstrated that these MT1-MMP-induced phenotypic changes were linked to Wnt5a, also associated with $\mathrm{EMT}^{[31]}$. These findings are supported by the aforementioned study by Jennbacken et al. ${ }^{[14]}$, which similarly described E-cadherin downregulation and $\mathrm{N}$-cadherin upregulation (both consistent with EMT) in the androgen-independent LNCaP-19 cell line, accompanied by increased MT1-MMP.

Degradation of the extracellular matrix $(E C M)$, and specifically laminin-10 (Ln-10), was explored by Bair et al. ${ }^{[32]}$. Laminins are key glycoprotein components of the ECM: providing structural support to the basal lamina in both normal prostate and malignant tissue. The authors point to evidence previously published describing upregulation of $\mathrm{Ln}-10$ as prostate cancer progresses from normal to PIN through to invasive cancer, suggesting a role for MT1-MMP in the invasion of prostate cancer ${ }^{[33]}$. Here, recombinant MT1-MMP (and MT1-MMP-expressing cells and tissues) was shown to cleave the $a 5$ chain of purified human Ln10 from its $350-k D a$ form into specific fragments. This cleavage was shown to decrease cell adhesion to purified Ln-10, and to increase transmigration of DU-145 cells through cleaved Ln-10 and thus the basal lamina. Increased invasion mediated by MT1MMP was also observed by Wang et al. ${ }^{[34]}$. Using cells engineered to overexpress MT1-MMP (namely PC3-LN4), invasion into type-I collagen gels in vitro was observed, through activation of pro-MMP2. PC3LN4 cells additionally proliferated at a faster rate than mock-transfected control cells when grown subcutaneously in nude mice.

Endo180 (UPARAP, urokinase-type plasminogen activator receptor-associated protein) regulates collagen remodelling and chemotactic cell migration through cooperation with MT1-MMP. A study by Kogianni et al. ${ }^{[35]}$ describes how Endo180 is 


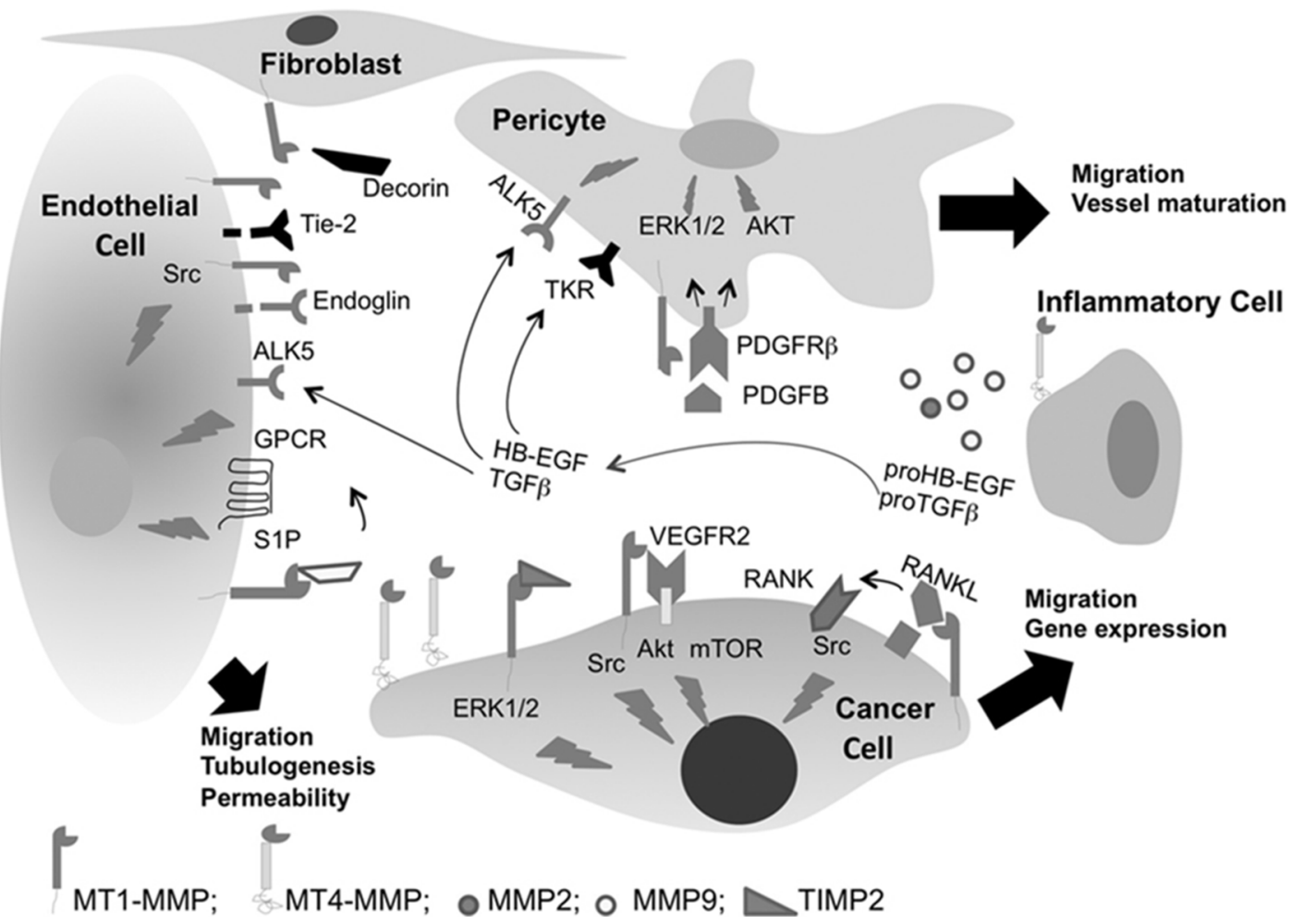

Figure 1: Membrane type-MMPs regulate cell signalling in cancer. MT1-MMP regulates cell migration through both ECM proteolysis and non-proteolyticdependent TIMP-2 activation of ERK1/2 pathway. MT1-MMP regulates VEGF gene expression through Src, Akt, and mTOR activation and stimulates tumor angiogenesis. Roles for MT-MMP expression are also associated with TGF $\beta$, Tie-2 and PDGFRß. Figure was originally published by Sounni et al. ${ }^{[28]}$. MT-MMP: membrane-type matrix metalloproteinases; ECM: extracellular matrix; VEGF: vascular endothelial growth factor

positively correlated with prostate cancer clinical risk and suggests that it is a stronger predictor of Gleason score than serum PSA. Endo180 disrupts epithelial cell contact and plays a potential role in EMT in prostate cancer. Endo180 and MT1-MMP coexpression was identified as strongly upregulated in the stroma of prostate cancer with low clinical risk, indicating that tumor-associated stromal fibroblasts can acquire the ability for effective collagen degradation and internalisation at the early stages of tumor development. These findings are interesting and add further support to prostate cancer cells influencing MT1-MMP expression in their surrounding microenvironment.

The transcription factor p53 is known to play significant roles as a tumor suppressor in cancer progression. Wang et al. ${ }^{[36]}$ considered the involvement of p53 in prostate cancer cell invasion and metastasis, using DU145 cells in which p53 was silenced by siRNA. Increased invasion and metastasis were observed in a series of in vitro experiments, including increased MT1-MMP expression and activity, along with that of MMP-2 and MMP-9. These findings are also consistent with the studies associating MT1-MMP with EMT, as demonstrated by reduced E-cadherin, increased $\mathrm{N}$-cadherin and enhanced vimentin staining. The authors additionally provide evidence that these effects are mediated via FAK-Src signalling.

A study by Sankpal et al. ${ }^{[37]}$ provides evidence for regulation of MT1-MMP by specificity protein 1 (Sp1). Sp1 is expressed in a number of different cancers, and plays key regulatory roles in processes associated with prostate cancer progression and metastasis. DU-145 cells were reported to express constitutively phosphorylated ERK, while PC 3 and PC $3 \mathrm{~N}$ cells express constitutively phosphorylated AKT/PKB and c-Jun NH2 terminal kinase (JNK). Interestingly, both MT1-MMP and Sp1 levels were decreased in PC3 cells when PI3K and JNK were inhibited, and MT1-MMP levels were decreased in DU-145 cells when MEK was inhibited. These results suggest Sp1-mediated transcriptional regulation of MT1-MMP in prostate cancer cell lines via differential signalling contro[ ${ }^{[13,37]}$. Sroka et al. ${ }^{[25]}$ additionally considered the relationship between IGF-1R and MT1-MMP in prostate cancer cells and tissues, the expression data for which were discussed earlier. IGF-1R has been identified to play a role in prostate cancer metastatic progression, through $\mathrm{PI} 3 \mathrm{~K}, \mathrm{MAP}$ kinase and ERK signalling ${ }^{[38]}$. Interestingly, decreased MT1-MMP expression at mRNA and 
protein level resulted from inhibition of IGF-1R (using picropodophyllin) in PC3N cells. Increased IGF-1R, when activated by IGF-1, led to increased MT1-MMP expression and activity following treatment of $\mathrm{LNCaP}$ cells with synthetic androgen R1881.

Reversion-inducing cysteine-rich protein with Kazal motifs (RECK), originally found to suppress transformation caused by the oncogene KRAS, is a glycoprotein tumor suppressor which inhibits metastasis and angiogenesis ${ }^{[39]}$. Previous studies have identified RECK as an inhibitor of various MMPs, including MT1-MMP ${ }^{[40]}$. Rabien et al ${ }^{[41]}$ identified RECK expression in prostate cancer cell lines and tissue and observeda significant decrease in malignant tissue. Significantly, RECK overexpression led to a dramatic reduction in tumor cell invasion and a decrease of pro-/active MT1-MMP expression (up to $53 \%$ of control).

Filiz and Dass ${ }^{[42]}$ demonstrated decreased expression of MT1-MMP associated with reduced pigment epithelium-derived factor (PEDF). The authors noted that PEDF had been previously found to be downregulated in prostate cancer patients (specifically in high-grade PIN, the most likely precursor of prostate cancer $)^{[43]}$. PEDF was examined for effects on PC3 cells, with increased adhesion to ECM protein collagen-I and decreased expression of phosphorylated FAK observed. Tumor cell invasion through collagen-I was also reduced. These findings were attributed to the decreased expression of MT1MMP.

Increased expression of both MT1-MMP and LIM kinase 1 (LIMK1) in prostate tumor tissues was reported by Tapia et al. ${ }^{[4]}$. LIMK1 is a downstream effector of Rho signalling, modulates actin dynamics and is overexpressed in prostate cancer cells, where it promotes invasion and metastasis. Results showed that treatment with ilomastat (broad-spectrum hydroxamate-based MMP inhibitor) reduced LIMK1induced invasion of benign prostate epithelial cells (BPH-1 cells) suggesting that the process is mediated by MMPs, notably MT1-MMP. Increased MT1-MMP expression in cells overexpressing LIMK1 was also reported, along with transcriptional activation and localisation of protein to the plasma membrane. LIMK1 was shown to physically associate with MT1-MMP and to co-localise with it in Golgi vesicles, thereby enabling transport of MT1-MMP to the cell surface ${ }^{[44]}$.

FGFR4 expression and polymorphism has been linked to prostate cancer progression and drug resistance ${ }^{[45]}$. In particular, a single nucleotide polymorphism (SNP) in codon 388 of the human FGFR4 gene has been linked to poor prognosis in prostate cancer patients. This SNP results in Gly388 being transformed to Arg in the transmembrane domain of the receptor, leading to prolonged FGFR4 receptor activation ${ }^{[46]}$. MT1MMP and FGFR4 were found to be co-expressed in the tumor edges and prostate carcinoma: MT1-MMP upregulation was observed in cancer cells ( 9 of 14) and/or reactive stroma (9 of 14), whereas FGFR4 expression was mainly found in the tumor cells. FGFR4-R388 was shown to enhance MT1-MMPmediated prostate cancer cell invasion. FGFR4 was thus also identified as playing a role in MT1-MMP. dependent ECM degradation and tumor progression involving EMT in vivo ${ }^{[47]}$.

MT1-MMP has additionally been associated with oxidative stress in prostate cancer cell lines. Nguyen et al. ${ }^{[48]}$ described how expression of MT1-MMP increased oxidative DNA damage via reactive oxygen species (ROS) in LNCaP and in DU145 cells, causing oxidative stress. The study confirmed the findings of others in demonstrating that MT1-MMP is associated with a more aggressive phenotype as illustrated by increased cell migration, invasion and anchorage-independent cell growth. Use of the scavenger $\mathrm{N}$-acetylcysteine to block ROS activity inhibited the MT1-MMP-mediated increase in cell migration and invasion. The authors additionally suggested a role for $\beta 1$-integrins in facilitating cell adhesion to matrix proteins, and that this was necessary for induction of ROS in MT1-MMPexpressing prostate cancer cells.

PTEN (phosphatase and tensin homologue deleted on chromosome ten) is a phosphatase enzyme involved in regulation of PI3K-Akt pathway signalling and thus cancer progression. Most metastatic prostate cancers exhibit loss-of-function mutations or deletions of this key tumor suppressor ${ }^{[49]}$. Kim et al. ${ }^{[50]}$ considered the role of PTEN inactivation on MT-MMP expression in prostate cancer. Mouse PTEN null cells exhibited up-regulation of MT1-MMP and MT3MMP gene expression (and the associated increased migration and invasion), and increased MT1-MMP protein expression in vivo. Interestingly, the MT1-MMP displayed by PTEN null cells exhibited a slow rate of turnover, which was thought to be due to differential O-glycosylation of the MT1-MMP hinge region modulating enzyme stability. MT1-MMP expression in PTEN null cells was additionally determined to be regulated by PI3K/Akt but not MAPK signalling, as determined by inhibitors of those pathways. A role for downstream pathway mTORC1 (positively regulates translation thereby promoting protein synthesis ${ }^{[51]}$ ) was predicted, given the upregulation of MT-MMP protein 
expression, but intriguingly inhibition by rapamycin (an mTOR inhibitor) actually upregulated MT1-MMP protein expression in PTEN null cells further, an effect that was reversed by Akt inhibition. The authors discuss this potential side effect of rapamycin, and note that similar observations have been reported elsewhere ${ }^{[50]}$.

As was the case with expression data, information regarding the roles of the other members of the MTMMP family is somewhat limited. Delassus et al. ${ }^{[12]}$ identified a series of prostate cancer progression modulators and engineered overexpression in prostate cancer cells (PC3) and others. Changes in gene expression of MT1-, MT3- and MT6-MMP were then evaluated. Over-expression of activator protein$2 \alpha$, interleukin 4 and $\mathrm{p} 16^{\mathrm{INK} 4 \alpha}$ had no effect on MTMMP expression. Fibulin1D led to down-regulation of MT1- and MT3-MMP (no reliable data for MT6MMP). Supporting the work of Wang et al. ${ }^{[36]}$, p53 overexpression led to reduced MT1-MMP expression (no reliable data for the other MT-MMPs evaluated). Overexpression of PTEN produced no change in MT1MMP expression, which is at odds with the data of Kim et al. ${ }^{[50]}$, with the caveat that cells in that study were mouse prostate cancer cells. Upregulation of MT3-MMP was observed, however. Furthermore, raf kinase inhibitor protein over-expression led to increased MT1-MMP, with no change detected for the others. Finally, over-expression of E-cadherin led to reduced expression of all three MT-MMPs. This finding thus reinforces the observations discussed earlier regarding the role of MT-MMPs in EMT (i.e. a phenotypic shift from $\mathrm{E}$ - to $\mathrm{N}$-cadherin expression $)^{[14,30,36]}$.

Lin et al. ${ }^{[52]}$ undertook genomic association studies to identify genetic variants, i.e. SNPs utilising data from the Cancer Genetic Markers of Susceptibility dataset, which includes data from 1,151 prostate cancer patients. The authors explain how SNP-SNP interactions, rather than studying individual SNPs, potentially have greater impact on unravelling the underlying mechanisms of complex disease ${ }^{[52]}$. Three important SNP-SNP interactions were identified, linking MT3-MMP to ROBO1, CSF-1 and EGFR. ROBO1 is a member of the roundabout immunoglobulin superfamily, and has been identified as playing key roles in prostate cancer progression ${ }^{[53]}$. It is cleaved by MMPs and translocates into the nucleus of cancer cells, which perhaps suggests a signalling role. The authors suggest that as no specific MMP has to-date been linked to ROBO1 cleavage, these data may have uncovered the potential for such a role for MT3-MMP. Colony stimulating factor- 1 has been associated with increased tumor angiogenesis ${ }^{[52]}$. Epidermal growth factor receptor (EGFR) plays an important role in regulating cancer cell growth and function, not least in prostate cancer, and is therapeutically important ${ }^{[54]}$. More recently, a much wider study by the same group using the prostate cancer PRACTICAL consortium data with approximately 21,000 patients, identified four key SNP-SNP interactions found to be associated with prostate cancer aggressiveness. Of relevance here, this study again linked MT3-MMP and EGFR ${ }^{[55]}$.

In addition, several studies point to an important role for MT-MMPs, and MT1-MMP in particular, in the processes associated with metastatic spread to bone in prostate cancer. This data will be considered in the following section.

\section{EXPRESSION AND ROLES OF MT-MMPS IN PROSTATE CANCER BONE METASTASIS}

It is suggested that more than $80 \%$ of patients with disseminated prostate cancer will present with metastasis to the bone ${ }^{[56,57]}$. Skeletal complications are thus one of the leading causes of morbidity and mortality in prostate cancer patients. The normal equilibrium between osteoblastic and osteolytic activity in bone is disturbed in prostate cancer, leading to changes that are likely to provide a favourable microenvironment for metastatic colonisation. Given the established roles for MMPs in normal bone remodelling, a role for MMPs in prostate cancer bone metastasis has long been proposed ${ }^{[58]}$. With this in mind, it is perhaps surprising that relatively little research has been directed to the MT-MMPs in this area to-date. MT1-MMP knock-out mice exhibit severe skeletal abnormalities, confirming a role in normal bone maintenance and development ${ }^{[59]}$. Given these roles in normal bone health, the expression of MT-MMPs in prostate cancer cells and tissues led Bonfil et al. ${ }^{[58]}$ to speculate as to the existence of a selective process in which prostate cancer cells may have a greater propensity to metastasise to bone, or whether the microenvironment within the bone itself may induce MMP expression in prostate cancer cells, after their arrival at the bone.

Nemeth et al. ${ }^{[60]}$ evaluated MT-MMP expression in clinical samples and the role of MMP activity in prostate cancer that had metastasised to the bone, using a preclinical mouse model of bone metastasis employing PC3 xenografts. MT1-MMP protein expression (as identified by immunohistochemical staining) was consistently observed in the 18 core bone biopsy samples from prostate cancer patients. In preclinical studies, single human foetal bone fragments were implanted subcutaneously in immunodeficient 
mice. After an interval of 4 weeks, PC3 cells were then injected directly into some of the implants, with/without initiation of daily treatment with broad-spectrum MMP inhibitor batimastat for 2 weeks. MT1-MMP expression was subsequently identified in PC3 bone tumors, localised primarily to tumor cells, with some stromal expression noted. The PC3 bone tumors were mostly osteolytic in nature, and MMP inhibition by batimastat reduced the number of osteoclasts per millimetre in these implants. The authors concluded that MT1-MMP activity in prostate cancer cells appears to be crucial in bone matrix turnover. This, together with metastatic tumor growth, appeared to be linked in cycle that is disrupted by MMP inhibition ${ }^{[60]}$.

A further correlation between MT1-MMP expression in prostate cancer cells and bone metastasis was also reported by Bonfil et al. ${ }^{[61]}$. MT1-MMP expression was abundant and consistent in tumor cells identified in paraffin sections of bone metastases from 20 prostate cancer patients (androgen independent disease). It should be noted that MT1-MMP expression was noted in endothelial cells, osteocytes, osteoblasts and stroma in matched normal bone samples, consistent with a role in bone development, albeit at expression levels which appear significantly lower than those exhibited by the tumor cells. Preclinical models were utilised to examine the role of MT1-MMP in metastatic bone colonisation of prostate cancer cells. MT1MMP was introduced into LNCaP cells, while it was silenced (using siRNA for MT1-MMP) in DU145 cells. MT1-MMP over-expression enhanced bone tumor growth (via intra-tibial injection) and associated osteolysis, while not affecting cell proliferation in vitro or subcutaneous tumor growth in vivo. This led the authors to conclude that MT1-MMP contributes a unique stimulatory effect on tumor growth in the bone microenvironment. Further studies utilising orthotopic models which better replicate the normal disease dissemination process are required to confirm these findings, but the authors nevertheless suggest the possibility that MT1-MMP activity may be worthy of pursuing as a therapeutic target for prostate cancer bone metastases. Furthermore, a role for RANKL was suggested: RANKL (receptor activator of NF$K B$ ligand) is a regulator of osteoclastogenesis, and its release in the bone microenvironment was linked to MT1-MMP activity. siRNA knockdown of MT1MMP inhibited bone tumor growth of DU145 cells and simultaneously led to osteogenesis, a phenomenon for which mechanistic information was not obtained. It was suggested that MT1-MMP inhibition may have shifted the balance toward bone formation simply by inhibition of osteolysis/osteoclastogenesis ${ }^{[61]}$.
Sabbota et al. ${ }^{[62]}$ subsequently followed up their initial findings and provided further evidence for a link between RANKL shedding and MT1-MMP protein expression, summarised in Figure 2. In this study, conditioned media from LNCaP cells expressing both RANKL and MT1-MMP was shown to enhance cell migration of LNCaP-C4-2b cells, which are MT1-MMP deficient. This was inhibited by osteoprotegerin (soluble decoy receptor of RANKL) and selective MT1-MMP inhibitor MIK-G2. The authors hypothesised that these findings indicated that MT1-MMP enhances tumor cell migration through initiation of an autocrine loop requiring RANKL shedding in prostate cancer cells. Evidence was also provided for a role for $\mathrm{Src}$ as a downstream mediator of RANKL ${ }^{[62]}$.

The importance of cadherin-11 in prostate cancer bone metastasis was considered by Huang et al. ${ }^{[63]}$. Cadherin-11 is an osteoblast cadherin, identified as being aberrantly expressed in prostate cancer cells derived from bone metastase ${ }^{[64]}$. LNCaP-C4-2B4 cells in which expression of cadherin-11 had been engineered demonstrated increased spread and intercalation into an osteoblast layer in vitro and exhibited enhanced migration and invasion. Downregulation of cadherin-11 in PC3 cells, which naturally express cadherin-11, decreased cell migration and invasion. A possible role for MT2-MMP was suggested, following gene array analysis of the LNCaP-C4-2B4 cells. Several genes related to invasion and metastasis were identified as upregulated, among which MT2-MMP was a prominent finding ${ }^{[63]}$. Interestingly, IGF-1 gene expression was also reported as upregulated, which supports the evidence provided by Sroka et al. ${ }^{[25]}$ relating to a role for IGF$1 \mathrm{R}$ in MT-MMP expression and activity, as discussed earlier.

MT-MMPs clearly play important roles in the development of metastatic bone deposits. Given that most patients with prostate cancer ultimately succumb to metastasis, a strategy to specifically target MT1-MMP-expression on tumor cells may prove an attractive means by which to address prostate cancer metastasis to bone.

\section{OPPORTUNITIES FOR DRUG TARGETING}

The expression of MT-MMPs in prostate cancer and associated bone metastases suggests an opportunity for targeted therapy. As an example, the Bonfil group focused on MT1-MMP expression in prostate cancer bone metastases, and suggested that the increased MT1-MMP activity was worthy of pursuing as a therapeutic strategy. The group later 


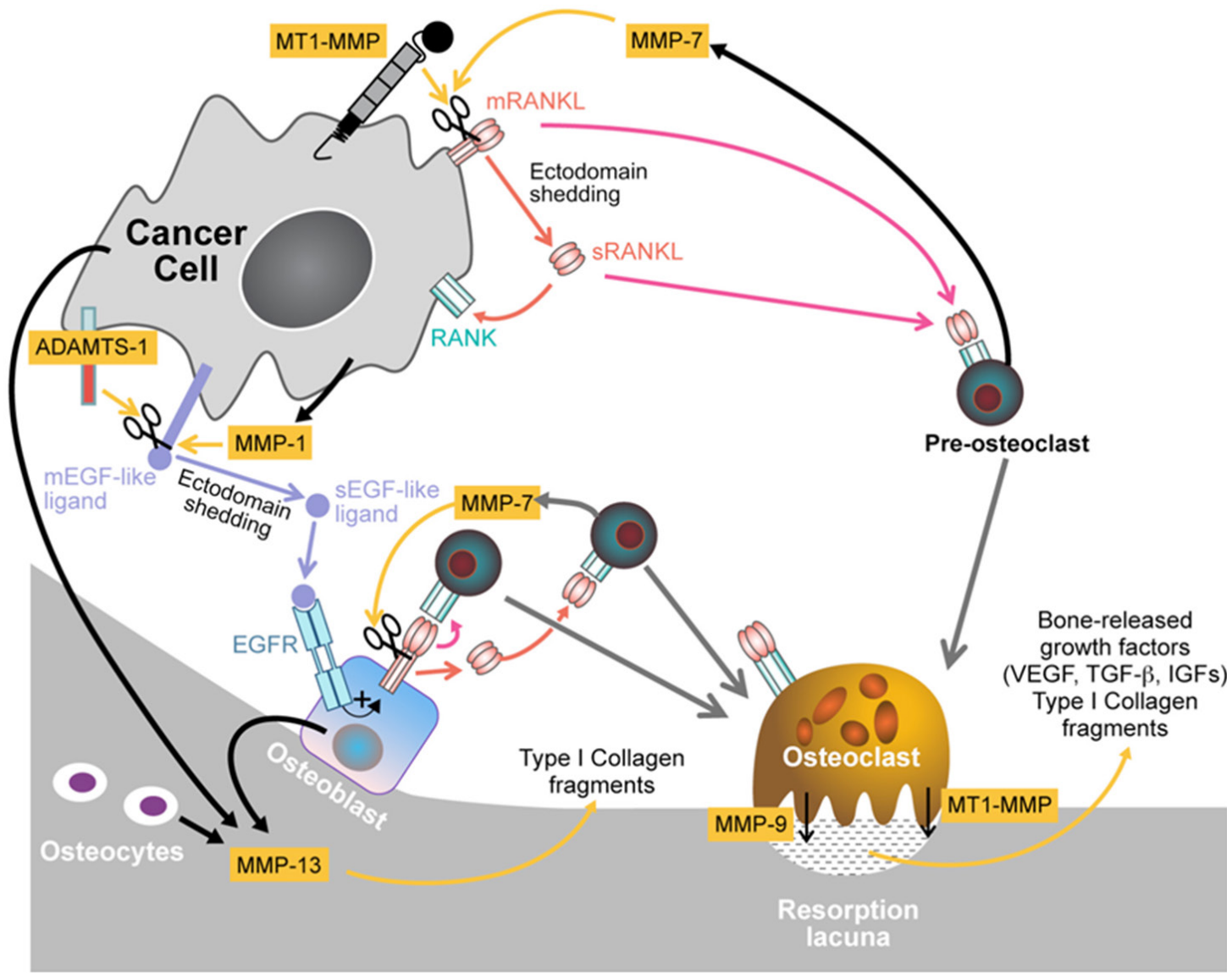

Figure 2: Diagram representing the most representative roles of MT1-MMP at bone metastatic sites. MT1-MMP expression by cancer cells results in proteolytic cleavage of tumor-associated membrane-bound RANKL (mRANKL), generating a soluble form of RANKL (sRANKL) that activates RANK favouring migration of tumor cells and osteoclastogenesis, respectively. Roles for MMP-7, MMP-9 and MMP-13 were also described. Reprinted by permission from Macmillan Publishers Ltd. ${ }^{[78]}$. MT-MMP: membrane-type matrix metalloproteinases

went on to propose a combination of Src inhibition with RANKL and/or selective MT1-MMP inhibition as a strategy, particularly for prostate cancer patients with bone metastases. Other strategies are worthy of investigation, utilising the knowledge that has been gained in understanding key pathways and how they interact with MT1-MMP activity, as have been discussed. Further study is required to fully understand the expression and roles of MT-MMPs in normal cells in the tumor microenvironment, however, given the possibility that tumor cells may induce expression in benign epithelial cells. Furthermore, very few studies contain data from healthy individuals for true "normal" tissue comparison.

MMP inhibition is an area that has been well explored in the past by big pharma, but has yet to fulfil its clinical potential. This is due to the complex roles of individual MMPs and their inter-connected compensatory mechanisms, poor clinical trial design, and drugs lacking exquisite selectivity ${ }^{[2,65]}$. Utilising MMP expression and proteolytic activity, however, is perhaps a more attractive approach ${ }^{[5,66]}$. This is especially true given the role of MMPs in angiogenesis and in maintenance of tumor vasculature ${ }^{[67,68]}$. While not specifically studied in prostate cancer, evidence for other cancers is compelling, particularly for MT1$\mathrm{MMP}^{[6,67]}$.

The need for novel therapeutics in metastatic prostate cancer is clear. The burden of drug toxicity endured by many patients, often elderly and frail, means that an emphasis must be placed on targeted agents with minimal side effects. Small molecule chemotherapeutics remain central to prostate cancer therapy, but despite some considerable recent advances, these new agents still suffer from a lack of selectivity and dose-limiting toxicities. There is therefore considerable interest in the development of prodrugs to tailor the pharmacokinetics of molecules in favour of tumor-selective drug targeting, thereby decreasing these dose-limiting side effects and enhancing therapeutic index ${ }^{[69]}$. Multiple reviews have been published covering a huge range of approaches for cancer drug delivery, but it is fair to say that 


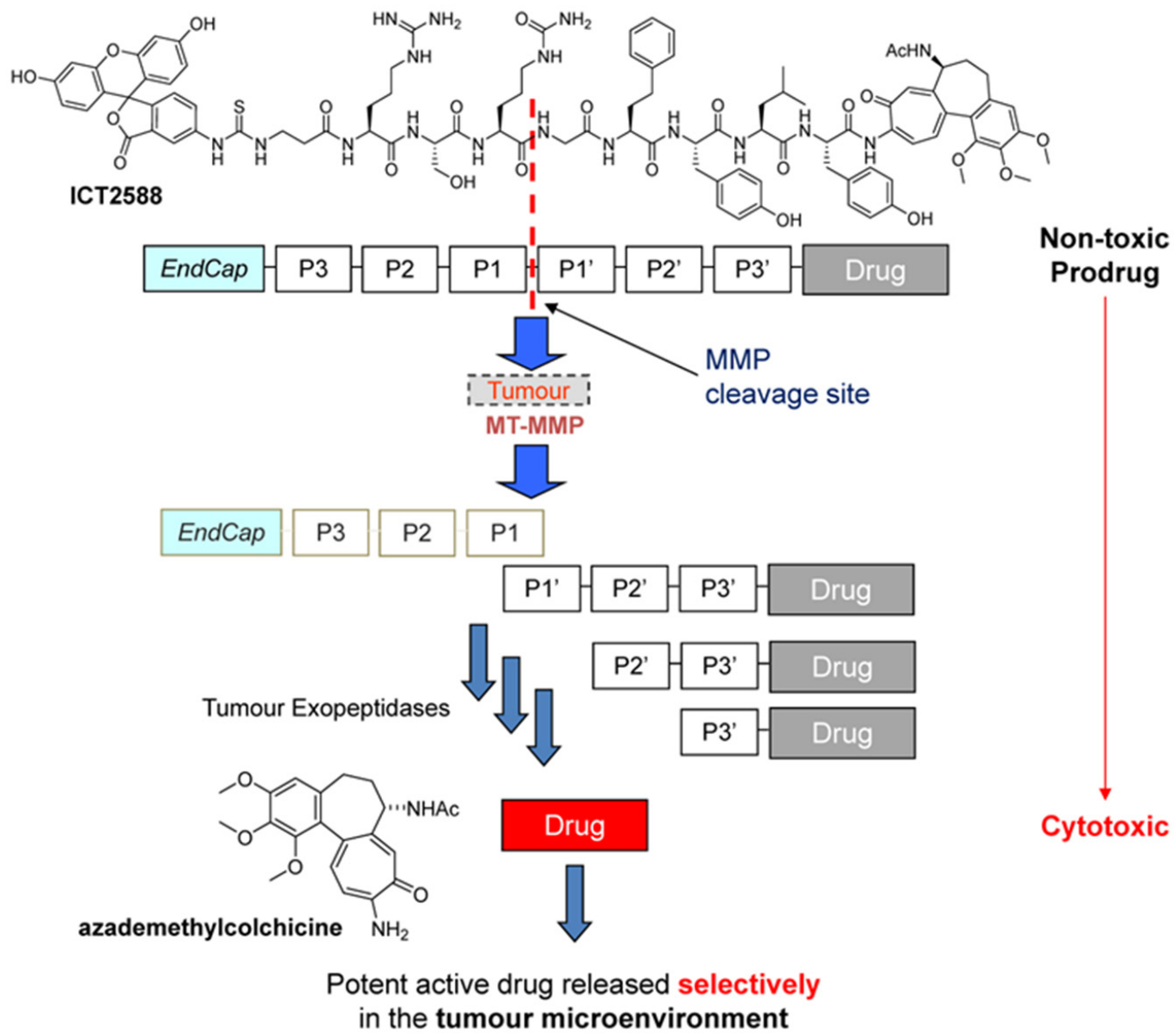

Figure 3: Structure of ICT2588 and MT-MMP targeting concept. Peptide conjugation renders the drug (azademethylcolchicine) pharmacologically inactive. Following initial MT-MMP recognition and cleavage, the remaining amino acids are metabolised to release the toxic drug selectively in the tumor microenvironment. MT-MMP: membrane-type matrix metalloproteinases

prodrug approaches specifically developed for prostate cancer are limited. MMP-activated prodrugs in prostate cancer are considered by Barve et al. ${ }^{[70]}$. Here the concept of attaching an MMP-recognition peptide to a drug is discussed. Peptide conjugation renders the drug inactive (thereby creating the prodrug) until such time that tumor-expressed MMPs recognise and cleave the peptide to release the drug. This area has considerable potential. Further examples are provided by Choi et al. ${ }^{[3]}$ and Law and Tung ${ }^{[4]}$.

ICT-2588 is a prodrug of azademethylcolchicine (an analogue of colchicine ${ }^{[71]}$ ) and is a potent antivascular agent [Figure 3]. Activated by MT1-MMP, ICT-2588 has shown promise in preclinical studies, successfully achieving enhanced therapeutic index ${ }^{[72]}$, an absence of cardiotoxicity ${ }^{[73]}$, and activity in a range of tumor types, not least prostate cancer (activity in PC3 xenografts in mouse models $)^{[73]}$. This potential for the treatment of prostate tumors led the authors to apply the same technology to paclitaxel, yielding ICT-3205 ${ }^{[74]}$. This agent provides for enhanced tumor delivery of paclitaxel in preclinical studies (PC3 xenograft in mice), realising 10-fold increases in tumor concentrations (as measured by in vivo pharmacokinetics studies) while decreasing the exposure of drug to normal tissues, and associated toxicities. Given the findings of the STAMPEDE prostate cancer trial supporting earlier use of taxanes in treatment of metastatic prostate cancer ${ }^{[75-77]}$, this approach is particularly timely.

While our understanding of the roles of MT-MMPs in prostate cancer and metastatic disease is growing all the time, much is still to be learnt. The potential for exploiting the proteolytic capacity of these enzymes is without question, but it remains to be seen whether a clinically useful drug molecule will emerge.

\section{DECLARATIONS}

\section{Acknowledgments}

The authors thank Dr. Klaus Pors (University of Bradford), Dr. Fiona Frame (University of York) and Dr. 
Jason Webber (Cardiff University) for organising the inaugural Prostate Cancer \&Tumor Microenvironment workshop (Cardiff, January 2017), which provided the catalyst for writing this review.

\section{Authors' contributions}

R.A. Falconer and P.M. Loadman contributed equally to writing this review.

\section{Financial support and sponsorship None.}

\section{Conflicts of interest}

RAF and PML declare that they are founding shareholders of Incanthera Ltd.

\section{Patient consent \\ Not applicable.}

\section{Ethics approval}

Not applicable.

\section{REFERENCES}

1. Gialeli C, Theocharis AD, Karamanos NK. Roles of matrix metalloproteinases in cancer progression and their pharmacological targeting. FEBS J 2011;278:16-27.

2. Vandenbroucke RE, Libert C. Is there new hope for therapeutic matrix metalloproteinase inhibition? Nat Rev Drug Discov 2014;13:904-27.

3. Choi KY, Swierczewska M, Lee S, Chen X. Protease-activated drug development. Theranostics 2012;2:156-78.

4. Law B, Tung CH. Proteolysis: a biological process adapted in drug delivery, therapy, and imaging. Bioconjug Chem 2009;20:1683-95.

5. Atkinson JM, Siller CS, Gill JH. Tumour endoproteases: the cutting edge of cancer drug delivery? Br J Pharmacol 2008;153:1344-52.

6. Itoh Y. Membrane-type matrix metalloproteinases: their functions and regulations. Matrix Biol 2015;44-46:207-23.

7. Gong Y, Chippada-Venkata UD, Oh WK. Roles of matrix metalloproteinases and their natural inhibitors in prostate cancer progression. Cancers 2014;6:1298-327.

8. Daja MM, Niu X, Zhao Z, Brown JM, Russell PJ. Characterization of expression of matrix metalloproteinases and tissue inhibitors of metalloproteinases in prostate cancer cell lines. Prostate Cancer Prostatic Dis 2003;6:15-26.

9. Iizumi T, Yazaki T, Kanoh S, Kondo I, Koiso K. Establishment of a new prostatic carcinoma cell line (TSU-Pr1). J Urol 1987;137:1304-6.

10. Nagakawa O, Murakami K, Yamaura T, Fujiuchi Y, Murata J, Fuse H, Saiki I. Expression of membrane-type 1 matrix metalloproteinase (MT1-MMP) on prostate cancer cell lines. Cancer Lett 2000;155:1739.

11. Jung M, Romer A, Keyszer G, Lein M, Kristiansen G, Schnorr D, Loening SA, Jung K. mRNA expression of the five membrane-type matrix metalloproteinases MT1-MT5 in human prostatic cell lines and their down-regulation in human malignant prostatic tissue. Prostate 2003;55:89-98.

12. Delassus GS, Cho H, Hoang S, Eliceiri GL. Many new down- and up-regulatory signaling pathways, from known cancer progression suppressors to matrix metalloproteinases, differ widely in cells of various cancers. J Cell Physiol 2010;224:549-58.
13. Sroka IC, Nagle RB, Bowden GT. Membrane-type 1 matrix metalloproteinase is regulated by $\mathrm{sp} 1$ through the differential activation of AKT, JNK, and ERK pathways in human prostate tumor cells. Neoplasia 2007;9:406-17.

14. Jennbacken K, Gustavsson H, Welen K, Vallbo C, Damber JE. Prostate cancer progression into androgen independency is associated with alterations in cell adhesion and invasivity. Prostate 2006;66:1631-40.

15. Gustavsson H, Welen K, Damber JE. Transition of an androgendependent human prostate cancer cell line into an androgenindependent subline is associated with increased angiogenesis. Prostate 2005;62:364-73

16. Coulson-Thomas VJ, Gesteira TF, Coulson-Thomas YM, Vicente CM, Tersariol IL, Nader HB, Toma L. Fibroblast and prostate tumor cell cross-talk: fibroblast differentiation, TGF-beta, and extracellular matrix down-regulation. Exp Cell Res 2010;316:3207-26.

17. Trudel D, Fradet Y, Meyer F, Harel F, Tetu B. Membrane-type-1 matrix metalloproteinase, matrix metalloproteinase 2 , and tissue inhibitor of matrix proteinase 2 in prostate cancer: identification of patients with poor prognosis by immunohistochemistry. Hum Pathol 2008;39:731-

18. Paterson RF, Ulbright TM, MacLennan GT, Zhang S, Pan CX, Sweeney CJ, Moore CR, Foster RS, Koch MO, Eble JN, Cheng L. Molecular genetic alterations in the laser-capture-microdissected stroma adjacent to bladder carcinoma. Cancer 2003;98:1830-6.

19. Neuhaus J, Schiffer E, Mannello F, Horn LC, Ganzer R, Stolzenburg JU. Protease expression levels in prostate cancer tissue can explain prostate cancer-associated seminal biomarkers-an explorative concept study. Int J Mol Sci 2017;18:E976.

20. Cardillo MR, Di Silverio F, Gentile V. Quantitative immunohistochemical and in situ hybridization analysis of metalloproteinases in prostate cancer. Anticancer Res 2006;26:97382.

21. Reis ST, Viana NI, Iscaife A, Pontes-Junior J, Dip N, Antunes AA, Guimaraes VR, Santana I, Nahas WC, Srougi M, Leite KR. Loss of TIMP-1 immune expression and tumor recurrence in localized prostate cancer. Int Braz J Urol 2015;41:1088-95.

22. Arpino V, Brock M, Gill SE. The role of TIMPs in regulation of extracellular matrix proteolysis. Matrix Biol 2015;44-46:247-54.

23. Reis ST, Antunes AA, Pontes-Junior J, Sousa-Canavez JM, Dall'Oglio MF, Piantino CB, Cruz JA, Morais DR, Srougi M, Leite KR. Underexpression of MMP-2 and its regulators, TIMP2, MT1MMP and IL-8, is associated with prostate cancer. Int Braz J Urol 2012;38:167-74

24. Upadhyay J, Shekarriz B, Nemeth JA, Dong Z, Cummings GD, Fridman R, Sakr W, Grignon DJ, Cher ML. Membrane type 1-matrix metalloproteinase (MT1-MMP) and MMP-2 immunolocalization in human prostate: change in cellular localization associated with high-grade prostatic intraepithelial neoplasia. Clin Cancer Res 1999:5:4105-10

25. Sroka IC, McDaniel K, Nagle RB, Bowden GT. Differential localization of MT1-MMP in human prostate cancer tissue: role of IGF-1R in MT1-MMP expression. Prostate 2008;68:463-76.

26. Riddick AC, Shukla CJ, Pennington CJ, Bass R, Nuttall RK, Hogan A, Sethia KK, Ellis V, Collins AT, Maitland NJ, Ball RY, Edwards DR. Identification of degradome components associated with prostate cancer progression by expression analysis of human prostatic tissues. Br J Cancer 2005;92:2171-80.

27. Kessenbrock K, Plaks V, Werb Z. Matrix metalloproteinases: regulators of the tumor microenvironment. Cell 2010;141:52-67.

28. Sounni NE, Paye A, Host L, Noel A. MT-MMPS as regulators of vesse stability associated with angiogenesis. Front Pharmacol 2011;2:111.

29. Larue L, Bellacosa A. Epithelial-mesenchymal transition in development and cancer: role of phosphatidylinositol 3' kinase/AKT pathways. Oncogene 2005;24:7443-54. 
30. Cao J, Chiarelli C, Richman O, Zarrabi K, Kozarekar P, Zucker S. Membrane type 1 matrix metalloproteinase induces epithelialto-mesenchymal transition in prostate cancer. $J$ Biol Chem 2008;283:6232-40.

31. Dissanayake SK, Wade M, Johnson CE, O’Connell MP, Leotlela PD, French AD, Shah KV, Hewitt KJ, Rosenthal DT, Indig FE, Jiang Y, Nickoloff BJ, Taub DD, Trent JM, Moon RT, Bittner M, Weeraratna AT. The Wnt5A/protein kinase $\mathrm{C}$ pathway mediates motility in melanoma cells via the inhibition of metastasis suppressors and initiation of an epithelial to mesenchymal transition. J Biol Chem 2007;282:17259-71.

32. Bair EL, Chen ML, McDaniel K, Sekiguchi K, Cress AE, Nagle RB, Bowden GT. Membrane type 1 matrix metalloprotease cleaves laminin-10 and promotes prostate cancer cell migration. Neoplasia 2005;7:380-9.

33. Udayakumar TS, Chen ML, Bair EL, Von Bredow DC, Cress AE, Nagle RB, Bowden GT. Membrane type-1-matrix metalloproteinase expressed by prostate carcinoma cells cleaves human laminin- 5 beta 3 chain and induces cell migration. Cancer Res 2003;63:2292-9.

34. Wang X, Wilson MJ, Slaton JW, Sinha AA, Ewing SL, Pei D. Increased aggressiveness of human prostate PC-3 tumor cells expressing cell surface localized membrane type-1 matrix metalloproteinase (MT1MMP). J Androl 2009;30:259-74.

35. Kogianni G, Walker MM, Waxman J, Sturge J. Endo180 expression with cofunctional partners MT1-MMP and UPAR-uPA is correlated with prostate cancer progression. Eur J Cancer 2009;45:685-93.

36. Wang Y, Zhang YX, Kong CZ, Zhang Z, Zhu YY. Loss of P53 facilitates invasion and metastasis of prostate cancer cells. Mol Cell Biochem 2013;384:121-7.

37. Sankpal UT, Goodison S, Abdelrahim M, Basha R. Targeting Sp1 transcription factors in prostate cancer therapy. Med Chem 2011;7:51825.

38. Larsson O, Girnita A, Girnita L. Role of insulin-like growth factor 1 receptor signalling in cancer. Br J Cancer 2005;92:2097-101.

39. Takahashi C, Sheng Z, Horan TP, Kitayama H, Maki M, Hitomi K, Kitaura Y, Takai S, Sasahara RM, Horimoto A, Ikawa Y, Ratzkin BJ, Arakawa T, Noda M. Regulation of matrix metalloproteinase-9 and inhibition of tumor invasion by the membrane-anchored glycoprotein RECK. Proc Natl Acad Sci U S A 1998;95:13221-6.

40. Miki T, Takegami Y, Okawa K, Muraguchi T, Noda M, Takahashi C. The reversion-inducing cysteine-rich protein with Kazal motifs (RECK) interacts with membrane type 1 matrix metalloproteinase and CD13/aminopeptidase $\mathrm{N}$ and modulates their endocytic pathways. $J$ Biol Chem 2007;282:12341-52.

41. Rabien A, Ergun B, Erbersdobler A, Jung K, Stephan C. RECK overexpression decreases invasive potential in prostate cancer cells. Prostate 2012;72:948-54.

42. Filiz G, Dass CR. Reduction in tumour cell invasion by pigment epithelium-derived factor is mediated by membrane type-1 matrix metalloproteinase downregulation. Pharmazie 2012;67:1010-4.

43. Qingyi Z, Lin Y, Junhong W, Jian S, Weizhou H, Long M, Zeyu S, Xiaojian G. Unfavorable prognostic value of human PEDF decreased in high-grade prostatic intraepithelial neoplasia: a differential proteomics approach. Cancer Invest 2009;27:794-801.

44. Tapia T, Ottman R, Chakrabarti R. LIM kinase1 modulates function of membrane type matrix metalloproteinase 1: implication in invasion of prostate cancer cells. Mol Cancer 2011;10:6.

45. Sahadevan K, Darby S, Leung HY, Mathers ME, Robson CN, Gnanapragasam VJ. Selective over-expression of fibroblast growth factor receptors 1 and 4 in clinical prostate cancer. $J$ Pathol 2007;213:82-90.

46. Wang J, Yu W, Cai Y, Ren C, Ittmann MM. Altered fibroblast growth factor receptor 4 stability promotes prostate cancer progression. Neoplasia 2008;10:847-56.

47. Sugiyama N, Varjosalo M, Meller P, Lohi J, Hyytiainen M, Kilpinen S, Kallioniemi O, Ingvarsen S, Engelholm LH, Taipale J, Alitalo K, Keski-Oja J, Lehti K. Fibroblast growth factor receptor 4 regulates tumor invasion by coupling fibroblast growth factor signaling to extracellular matrix degradation. Cancer Res 2010;70:7851-61.

48. Nguyen HL, Zucker S, Zarrabi K, Kadam P, Schmidt C, Cao J. Oxidative stress and prostate cancer progression are elicited by membrane-type 1 matrix metalloproteinase. Mol Cancer Res 2011;9:1305-18

49. McCall P, Witton CJ, Grimsley S, Nielsen KV, Edwards J. Is PTEN loss associated with clinical outcome measures in human prostate cancer? Br J Cancer 2008;99:1296-301.

50. Kim S, Huang W, Mottillo EP, Sohail A, Ham YA, ConleyLacomb MK, Kim CJ, Tzivion G, Kim HR, Wang S, Chen YQ, Fridman R. Posttranslational regulation of membrane type 1-matrix metalloproteinase (MT1-MMP) in mouse PTEN null prostate cancer cells: enhanced surface expression and differential O-glycosylation of MT1-MMP. Biochim Biophys Acta 2010;1803:1287-97.

51. Ma XM, Blenis J. Molecular mechanisms of mTOR-mediated translational control. Nat Rev Mol Cell Biol 2009;10:307-18.

52. Lin HY, Amankwah EK, Tseng TS, Qu X, Chen DT, Park JY. SNPSNP interaction network in angiogenesis genes associated with prostate cancer aggressiveness. PLoS One 2013;8:e59688.

53. Parray A, Siddique HR, Kuriger JK, Mishra SK, Rhim JS, Nelson HH, Aburatani H, Konety BR, Koochekpour S, Saleem M. ROBO1, a tumor suppressor and critical molecular barrier for localized tumor cells to acquire invasive phenotype: study in African-American and Caucasian prostate cancer models. Int J Cancer 2014;135:2493-506.

54. Di Lorenzo G, Tortora G, D’Armiento FP, De Rosa G, Staibano S, Autorino R, D'Armiento M, De Laurentiis M, De Placido S, Catalano G, Bianco AR, Ciardiello F. Expression of epidermal growth factor receptor correlates with disease relapse and progression to androgenindependence in human prostate cancer. Clin Cancer Res 2002;8:343844.

55. Lin HY, Chen DT, Huang PY, Liu YH, Ochoa A, Zabaleta J, Mercante DE, Fang Z, Sellers TA, Pow-Sang JM, Cheng CH, Eeles R, Easton D, Kote-Jarai Z, Amin Al Olama A, Benlloch S, Muir K, Giles GG, Wiklund F, Gronberg H, Haiman CA, Schleutker J, Nordestgaard BG, Travis RC, Hamdy F, Pashayan N, Khaw KT, Stanford JL, Blot WJ, Thibodeau SN, Maier C, Kibel AS, Cybulski C, Cannon-Albright L, Brenner H, Kaneva R, Batra J, Teixeira MR, Pandha H, Lu YJ, Consortium P, Park JY. SNP interaction pattern identifier (SIPI): an intensive search for SNP-SNP interaction patterns. Bioinformatics 2017;33:822-33.

56. Gandaglia G, Karakiewicz PI, Briganti A, Passoni NM, Schiffmann J, Trudeau V, Graefen M, Montorsi F, Sun M. Impact of the site of metastases on survival in patients with metastatic prostate cancer. Eur Urol 2015;68:325-34.

57. Manca P, Pantano F, Iuliani M, Ribelli G, De Lisi D, Danesi R, Del Re M, Vincenzi B, Tonini G, Santini D. Determinants of bone specific metastasis in prostate cancer. Crit Rev Oncol Hematol 2017;112:59-66.

58. Bonfil RD, Fridman R, Mobashery S, Cher ML. Are matrix metalloproteinases relevant therapeutic targets for prostate cancer bone metastasis? Curr Oncol 2008;15:188-92.

59. Holmbeck K, Bianco P, Caterina J, Yamada S, Kromer M, Kuznetsov SA, Mankani M, Robey PG, Poole AR, Pidoux I, Ward JM, BirkedalHansen H. MT1-MMP-deficient mice develop dwarfism, osteopenia, arthritis, and connective tissue disease due to inadequate collagen turnover. Cell 1999;99:81-92.

60. Nemeth JA, Yousif R, Herzog M, Che M, Upadhyay J, Shekarriz B, Bhagat S, Mullins C, Fridman R, Cher ML. Matrix metalloproteinase 
activity, bone matrix turnover, and tumor cell proliferation in prostate cancer bone metastasis. J Natl Cancer Inst 2002;94:17-25.

61. Bonfil RD, Dong Z, Trindade Filho JC, Sabbota A, Osenkowski P, Nabha S, Yamamoto H, Chinni SR, Zhao H, Mobashery S, Vessella RL, Fridman R, Cher ML. Prostate cancer-associated membrane type 1-matrix metalloproteinase: a pivotal role in bone response and intraosseous tumor growth. Am J Pathol 2007;170:2100-11.

62. Sabbota AL, Kim HR, Zhe X, Fridman R, Bonfil RD, Cher ML. Shedding of RANKL by tumor-associated MT1-MMP activates Srcdependent prostate cancer cell migration. Cancer Res 2010;70:555866.

63. Huang CF, Lira C, Chu K, Bilen MA, Lee YC, Ye X, Kim SM, Ortiz A, Wu FL, Logothetis CJ, Yu-Lee LY, Lin SH. Cadherin-11 increases migration and invasion of prostate cancer cells and enhances their interaction with osteoblasts. Cancer Res 2010;70:4580-9.

64. Kawaguchi J, Azuma Y, Hoshi K, Kii I, Takeshita S, Ohta T, Ozawa H, Takeichi M, Chisaka O, Kudo A. Targeted disruption of cadherin-11 leads to a reduction in bone density in calvaria and long bone metaphyses. J Bone Miner Res 2001;16:1265-71.

65. Cathcart J, Pulkoski-Gross A, Cao J. Targeting matrix metalloproteinases in cancer: bringing new life to old ideas. Genes Dis 2015;2:26-34.

66. Vartak DG, Gemeinhart RA. Matrix metalloproteases: underutilized targets for drug delivery. J Drug Target 2007;15:1-20.

67. Deryugina EI, Quigley JP. Tumor angiogenesis: MMP-mediated induction of intravasation- and metastasis-sustaining neovasculature. Matrix Biol 2015;44-46:94-112.

68. Lafleur MA, Handsley MM, Knauper V, Murphy G, Edwards DR. Endothelial tubulogenesis within fibrin gels specifically requires the activity of membrane-type-matrix metalloproteinases (MT-MMPs). $J$ Cell Sci 2002;115:3427-38.

69. Zawilska JB, Wojcieszak J, Olejniczak AB. Prodrugs: a challenge for the drug development. Pharmacol Rep 2013;65:1-14.

70. Barve A, Jin W, Cheng K. Prostate cancer relevant antigens and enzymes for targeted drug delivery. J Control Release 2014;187:11832 .

71. Bhattacharyya B, Panda D, Gupta S, Banerjee M. Anti-mitotic activity of colchicine and the structural basis for its interaction with tubulin.
Med Res Rev 2008;28:155-83.

72. Atkinson JM, Falconer RA, Edwards DR, Pennington CJ, Siller CS, Shnyder SD, Bibby MC, Patterson LH, Loadman PM, Gill JH. Development of a novel tumor-targeted vascular disrupting agent activated by membrane-type matrix metalloproteinases. Cancer Res 2010;70:6902-12

73. Gill JH, Loadman PM, Shnyder SD, Cooper P, Atkinson JM, Ribeiro Morais G, Patterson LH, Falconer RA. Tumor-targeted prodrug ICT2588 demonstrates therapeutic activity against solid tumors and reduced potential for cardiovascular toxicity. Mol Pharm 2014;11:1294-300.

74. Loadman PM, Gimenez-Warren J, Mitchell A, Race AD, Spencer JA Shnyder SD, Gill JH, Falconer RA. Improved delivery of paclitaxel to prostate tumors: a membrane-type matrix metalloproteinase (MTMMP)-targeted approach. Cancer Res 2016;76:2054.

75. Graff JN, Beer TM. Should docetaxel be administered earlier in prostate cancer therapy? Expert Rev Anticancer Ther 2015;15:977-9.

76. James ND, Spears MR, Clarke NW, Dearnaley DP, De Bono JS Gale J, Hetherington J, Hoskin PJ, Jones RJ, Laing R, Lester JF, McLaren D, Parker CC, Parmar MK, Ritchie AW, Russell JM, Strebel RT, Thalmann GN, Mason MD, Sydes MR. Survival with newly diagnosed metastatic prostate cancer in the "docetaxel rra": data from 917 Patients in the control arm of the STAMPEDE Trial (MRC PR08, CRUK/06/019). Eur Urol 2015;67:1028-38

77. James ND, Sydes MR, Clarke NW, Mason MD, Dearnaley DP, Spears MR, Ritchie AW, Parker CC, Russell JM, Attard G, de Bono J, Cross W, Jones RJ, Thalmann G, Amos C, Matheson D, Millman R, Alzouebi M, Beesley S, Birtle AJ, Brock S, Cathomas R, Chakraborti P, Chowdhury S, Cook A, Elliott T, Gale J, Gibbs S, Graham JD, Hetherington J, Hughes R, Laing R, McKinna F, McLaren DB, O’Sullivan JM, Parikh O, Peedell C, Protheroe A, Robinson AJ, Srihari N, Srinivasan R, Staffurth J, Sundar S, Tolan S, Tsang D, Wagstaff J, Parmar MK. Addition of docetaxel, zoledronic acid, or both to firstline long-term hormone therapy in prostate cancer (STAMPEDE): survival results from an adaptive, multiarm, multistage, platform randomised controlled trial. Lancet 2016;387:1163-77.

78. Bonfil RD, Cher ML. The role of proteolytic enzymes in metastatic bone disease. IBMS BoneKEy 2011;8:16-36. 